\title{
Characterization of wind power resource in the United States
}

\author{
U. B. Gunturu and C. A. Schlosser
}

The MIT Joint Program on the Science and Policy of Global Change, Massachusetts Institute of Technology, Cambridge, MA 02139, USA

Correspondence to: U. B. Gunturu (bhaskar@mit.edu)

Received: 7 January 2012 - Published in Atmos. Chem. Phys. Discuss.: 13 March 2012

Revised: 26 August 2012 - Accepted: 14 September 2012 - Published: 24 October 2012

\begin{abstract}
Wind resource in the continental and offshore United States has been reconstructed and characterized using metrics that describe, apart from abundance, its availability, persistence and intermittency. The Modern Era Retrospective-Analysis for Research and Applications (MERRA) boundary layer flux data has been used to construct wind profile at $50 \mathrm{~m}, 80 \mathrm{~m}, 100 \mathrm{~m}, 120 \mathrm{~m}$ turbine hub heights. The wind power density (WPD) estimates at $50 \mathrm{~m}$ are qualitatively similar to those in the US wind atlas developed by the National Renewable Energy Laboratory (NREL), but quantitatively a class less in some regions, but are within the limits of uncertainty. The wind speeds at $80 \mathrm{~m}$ were quantitatively and qualitatively close to the NREL wind map. The possible reasons for overestimation by NREL have been discussed. For long tailed distributions like those of the WPD, the mean is an overestimation and median is suggested for summary representation of the wind resource.

The impact of raising the wind turbine hub height on metrics of abundance, persistence, variability and intermittency is analyzed. There is a general increase in availability and abundance of wind resource but there is an increase in intermittency in terms of level crossing rate in low resource regions.
\end{abstract}

\section{Introduction}

\subsection{Characterization of wind resource}

The US national wind energy resource estimates were developed by the National Renewable Energy Laboratory (NREL) (Elliott et al., 1987, 1991) and the wind resource was remapped at a higher resolution for the midwestern US (Schwartz and Elliot, 2001). Several data sources were used to collect the wind data. Most importantly, National Climate Data Center (NCDC) archives constituted the major proportion of the data. The atlas preferred to use wind power density and not wind speed as a measure of the resource because the former combines the effect of changes in air density. The air density was estimated using measured temperature and station pressure and the equation of state. When temperature and pressure were not available, air density at the surface was assumed to be $1.225 \mathrm{~kg} \mathrm{~m}^{-3}$ and extrapolated to the height of the wind speed record. The wind speed at the surface or $10 \mathrm{~m}$ was adjusted to $50 \mathrm{~m}$ using an exponential law with an exponent of 1/7. Because the seasonal and geographical variation of density is not taken into consideration, the wind resource has been overestimated in the wind atlas. Further, the wind atlas depicts the mean WPD. Below, we discuss some of the key caveats when using such distributions to estimate wind power resources.

\subsubsection{Implications of Weibull distribution}

Several researchers used the two-parameter Weibull distribution to fit wind speed frequency distributions (Elliott et al., 1987; Schwartz and Elliot, 2001; Dorvlo, 2002; Lun and Lam, 2000; Pavia and O'Brien, 1986; Chang et al., 2003; Ucar and Balo, 2009; Pryor and Barthelmie, 2010; Zaharim et al., 2009; Eskin et al., 2008).

The Weibull distribution (Eq. 1), which is commonly used to fit wind speeds, is a function of two parameters: $c$, the scale factor and $k$ the shape factor which is dimensionless. Here, $V$ is the wind speed.

$$
f(V)=\left(\frac{k}{c}\right)\left(\frac{V}{c}\right)^{k-1} \exp \left[-\left(\frac{V}{c}\right)^{k}\right]
$$


Some of the merits cited are the flexibility and ease of use as only two parameters need to be determined to fit the distribution. Tuller and Brett (1984) describe the conditions under which wind speeds approximately follow Weibull distribution. He et al. (2010) pointed out that buoyancy fluxes force the distribution away from Weibull behavior. They reported that the daytime winds are near-Weibull but the nighttime winds showed greater positive skewness than the Weibull distribution. Thus the use of Weibull distribution underestimates the frequencies of the higher wind speeds. As argued by Morrissey et al. (2010), the first step in computing a WPD distribution is to study the WPD distribution rather than the wind speed distribution. Jaramillo and Borja (2004) found that the two-parameter Weibull distribution can not be generalized since it is not accurate in the case of some wind regimes. Morrissey et al. (2010) give an example of wind speed distribution for Boise City, Oklahoma and point out that the two-parameter Weibull distribution does not fit the wind speed distribution well. When the Weibull distribution is used for that wind speed data, the frequencies of lower speeds are underestimated and those of the higher speeds are overestimated which results in an overestimation of the resource.

\subsubsection{Shape factor}

The shape factor of the Weibull distribution has a great impact on the fit of wind speeds because as shape factor increases, the tail of the Weibull distribution decreases. Thus, the extreme wind speeds decrease and the distribution transforms towards a normal one. Usually, the measured wind speeds are fit to the Weibull distribution and the mean WPD is computed using the Weibull distribution. This is done because the wind speed record is usually small. In doing so, the WPD is not estimated accurately because the Weibull is only an approximate fit for the wind speeds and also because the WPD involves cube of the wind speed, any error in wind speed gets amplified in WPD. Also, sometimes, as in the US wind energy atlas (Elliott et al., 1987), a constant shape factor of 2 is assumed for using the Weibull distribution. The implication is that if the actual shape factor is less than 2, the frequencies of very high wind speeds are lowered and the mean WPD is underestimated. Similarly, if the actual shape factor is greater than 2 , the frequencies of very high wind speeds are increased and the mean WPD is overestimated.

The skewness of a Weibull distribution is only a function of its shape parameter $c$. Hennessey Jr. (1977) studied the statistical behavior of wind speeds and WPD and inferred that the locations that have the highest mean wind speeds have the lowest shape parameters for the wind distributions and hence greatest skewness. Thus, using a constant shape parameter of $c=2$ increases the WPD in the distribution. Because of the cubic relationship between the WPD and the wind speed, small changes in wind speed can mean large increases in the wind power density.
To compute the wind resource in a geographical region, most researchers used measurements using dedicated meteorological towers, airport measurements or the observational data from the National Climatic Data Center (NCDC) (Elliott et al., 1987; Archer and Jacobson, 2003, 2007; Brower, 2008). Since the data size in most of these records is small, the data is fit to the Weibull distribution. Also, such small records fail to capture the longer term variations in wind speeds. For example, Atkinson et al. (2006) has studied the correlation between the North Atlantic Oscillation (NAO) and wind speeds in Europe and found that there is a wind flood during the early 1990s followed by a return to the long term average after 1995. Thus, if the measurements taken during this high wind period are used to construct the wind resource maps, the wind resource is overestimated.

\subsubsection{Wind droughts}

Boccard (2009) pointed out that the average wind capacity factors in several countries in Europe have been estimated to be in the range $30-35 \%$ while the realized values are very low, averaging at $21 \%$. For the US, he reports $25.7 \%$ for the whole US and $22.45 \%$ for California while that claimed by The American Wind Energy Association (2005) is 35\%. He argues that one of the reason for the overestimation of wind energy potential is the short record of observations used to estimate. He reasons that atmospheric oscillations like NAO need to be taken into account (Atkinson et al., 2006).

\subsubsection{Characterizations or variables used to describe the wind resource}

In many of the studies preceding this, a mean value was used as a measure of the central tendency of the WPD. A cursory plot of the histogram of WPD at a site or for a region shows that it is a highly skewed and long-tailed distribution. Thus, the mean may not faithfully represent the distribution's central tendency of the WPD accurately. Thus, estimates of backup or power produced tend not to be estimated accurately. Further, Hennessey Jr. (1977) showed that wind power studies based only on the total mean WPD do not give an accurate picture of the wind power potential of a site and omit valuable information in terms of intermittency and variability.

Many researchers used data from meteorological towers or observations from airports. Many of these observations are at different heights, and different schemes have been used to adjust the wind speeds to the wind turbine hub heighs. Kiss and Jánosi (2008) used the ECMWF's (European Center for Medium-range Weather Forecasting) ERA-40 (ECMWF ReAnalysis) reanalysis eastward and northward winds at $10 \mathrm{~m}$ to study wind field statistics over Europe. Larsen and Mann (2009) also used reanalysis data from NCEP/NCAR (National Center for Environmental Prediction/National Center for Atmospheric Research) to estimate the geostrophic wind 
and extrapolated the geostrophic wind to $10 \mathrm{~m}$ height. Elliott et al. (1987) used a power law with the exponent $1 / 7$ as mentioned above. Archer and Jacobson (2007) used the upper air measurements from balloons and rawinsondes at the nearest meteorological stations to extrapolate the wind speeds at $10 \mathrm{~m}$ to the hub height at $50 \mathrm{~m}$ or $80 \mathrm{~m}$. Similarly, many researchers used a power or logarithmic law assuming roughness length and friction velocity in the boundary layer that did not vary with seasons, terrain and stability of the atmosphere.

To overcome these shortcomings, we chose to use the Modern Era Retrospective-Analysis for Research and Applications (MERRA) reanalysis data (Rienecker et al., 2011) that has a resolution of $1 / 2^{\circ} \times 2 / 3^{\circ}$ and a long record of hourly data for 31 years to reconstruct the wind field at $50 \mathrm{~m}$, $80 \mathrm{~m}, 100 \mathrm{~m}, 120 \mathrm{~m}$. The details of the methodology adapted for this reconstruction of the WPD field across the US are described in the Sect. 2. Instead of using the wind speeds, we computed the wind speed at different heights using boundary layer flux data and boundary layer similarity theory.

While trying to look at the wind resource as a system, we tried to characterize the reliability using some metrics from reliability theory. Most of the wind atlases of many countries describe the wind resource in terms of only the mean WPD and only some atlases show maps of the variability in terms of the standard deviation. In this attempt, we studied the statistics of the episode lengths of the WPD runs using a threshold of $200 \mathrm{~W} \mathrm{~m}^{-2}$ (Gustavson, 1979). Although these statistics have not been looked at earlier, these metrics that describe the persistence of WPD are important considerations considering the enormous impact variability of wind power has on the power grid, electricity prices and the resource itself. Further, the level crossing statistics of the wind power density are presented, as these raise important considerations in the maintenance of backup for the times of lulls.

\section{Methodology}

The domain considered for the study spans the contiguous states of the US bound between $20^{\circ} \mathrm{N}$ and $50^{\circ} \mathrm{N}$ latitudes and $130^{\circ} \mathrm{W}$ and $60^{\circ} \mathrm{W}$ longitudes. This domain also takes into account the offshore regions on the east and west side of the US.

\subsection{MERRA Data}

The data needed for this study has been taken from the MERRA, which is a reconstruction of the atmospheric state by assimilating observational data from different platforms into a global model (Rienecker et al., 2011). The data assimilation included conventional data from many sources and also data from several trains of satellites. MERRA was conducted at the NASA Center for Climate Simulation as three separate analysis streams. The initial key goal of MERRA was to improve upon the water cycle analysis in previous generation reanalyses like NCEP Reanalysis 1 and 2 and, ERA-40. Overall, MERRA aims to provide a more accurate dataset using the comprehensive suite of satellite based information for climate and atmospheric research. The present data set has been constructed with GEOS-5 (Goddard Earth Observing System-5) Atmospheric Data Assimilation System (version 5.2.0) (ADAS). The system consists of the GEOS-5 model and the Grid-point Statistical Interpolation (GSI) analysis. GSI is a system developed by Global Modeling and Assimilation Office (GMAO) and NOAA's (National Oceanic and Atmospheric Administration) National Centers for Environmental Prediction jointly. The data set has a spatial resolution of $1 / 2^{\circ} \times 2 / 3^{\circ}$, and a time resolution of an hour. The data spans the time from 00:30 h UTC on 1 January 1979 to 23:30 h UTC on 31 December 2009. Thus the dataset provides an opportunity to look at the variation of the winds over several scales up to the decadal scale. The dataset is averaged in time. So, if there are any jumps in any of the quantities at scales lower than $1 \mathrm{~h}$, they will be represented in the average.

WPD is used to describe wind resource as it is independent of the wind turbine characteristics and also because it will ease comparison with other estimates like that by NREL. It indicates how much wind energy can be harvested at a location by a wind turbine and has the units $\mathrm{W} \mathrm{m}^{-2}$. The WPD at each time step is calculated using the expression:

$P=\frac{1}{2} \rho V^{3}$

where $P, \rho$ and $V$ are the wind power density, density of the atmosphere and the wind speed at the point. MERRA dataset has hourly density $\rho$ and wind speed $V$ values. The MERRA 2D surface turbulent flux diagnostics data set provides these values at a single level corresponding to the top of the surface layer. We use this wind speed data at the top of the surface layer to illustrate the analysis that we apply at different heights.

\subsubsection{Wind resource at different heights}

During the 1990s the general wind turbine height was $50 \mathrm{~m}$. With the advancement of technology, the hub height of the turbine could be raised to $80 \mathrm{~m}, 100 \mathrm{~m}$ and $120 \mathrm{~m}$ although turbines of $80 \mathrm{~m}$ hub height are more common now. Thus, the estimation of wind resource and its variability at these different heights is imperative to study the behavior of wind power over the US.

The similarity theory in boundary layer dynamics is used to estimate the wind speed at the different heights.

The atmospheric boundary layer is controlled most importantly by (Stull, 1988) the aerodynamic roughness length of the surface and the surface heat flux. Further, the stability of the atmosphere also plays a key role in the maintenance of 
winds in the boundary layer. The shear-stress in the boundary layer is estimated by the friction velocity $u_{*}$.

Using these variables, the wind speed at a height $z$ in the boundary layer is expressed as

$V_{z}=\left(\frac{u_{*}}{k}\right)\left[\log \left(\frac{z-d}{z_{0}}\right)-\psi\right]$

where $d$ is the displacement height, $z_{0}$ is the roughness length and $k$ is the von Karman constant. $z$ is the height at which the wind speed is estimated.

$\psi$ depends on the stability of the boundary layer. For this study, the boundary layer is assumed to be neutrally stable. This assumption is reasonable because at the high wind speeds at which wind power is generated, the boundary layer has large wind shear and so, the boundary layer is approximately neutrally stable. Thus, Eq. (3) becomes:

$V_{z}=\left(\frac{u_{*}}{k}\right) \log \left[\frac{(z-d)}{z_{0}}\right]$.

\subsection{Resource metrics}

Taking the hourly-average values of $u_{*}, d, z_{0}$, the wind speed at height $z$ is determined. Using this relationship, the wind speed at the heights $50 \mathrm{~m}, 80 \mathrm{~m}, 100 \mathrm{~m}$ and $120 \mathrm{~m}$ was computed. Thus, a dataset of hourly wind speed from $00: 30 \mathrm{~h}$ on 1 January 1979 to $23: 30 \mathrm{~h}$ on 31 December 2009 has been constructed for each of the heights. It is assumed that the air density does not differ appreciably at these heights through the well-mixed boundary layer. Thus, using the air density at the surface $\rho$ and the wind speed computed using the logarithmic wind profile above, the wind power density at these heights is estimated using:

$P_{z}=\frac{1}{2} \rho V_{z}^{3}$

The US wind atlas developed by NREL (Elliott et al., 1987, 1991) used a power law for wind speed or wind power density of the form:

$\left(\frac{\bar{V}_{r}}{\bar{V}_{a}}\right)=\left(\frac{z_{r}}{z_{a}}\right)^{\alpha} \quad$ or $\quad\left(\frac{\bar{P}_{r}}{\bar{P}_{a}}\right)=\left(\frac{z_{r}}{z_{a}}\right)^{S \alpha}$

where $\bar{V}_{a}$ and $\bar{V}_{r}$ are the mean wind speeds and $\bar{P}_{a}$ and $\bar{P}_{r}$ are the mean WPD at heights $z_{a}$ and $z_{r}$ (the anemometer height $z_{a}$ and the reference level $z_{r}$ respectively) and $\alpha$ is the power law exponent. $S$ is the nondimensional wind shear. Based on empirical fits of the anemometer measurements at some airport locations, the value of $1 / 7$ was used for the exponent $\alpha$ to adjust the mean wind speed to $50 \mathrm{~m}$ height. But Schwartz and Elliot (2005), using anemometers mounted at higher hub heights, found that the shear exponent $\alpha$ is significantly higher than $1 / 7$ used in making the wind atlas. As described above, our estimates take into account the effects of surface heat flux on the friction velocity, the time variation in displacement height and roughness length. As such,

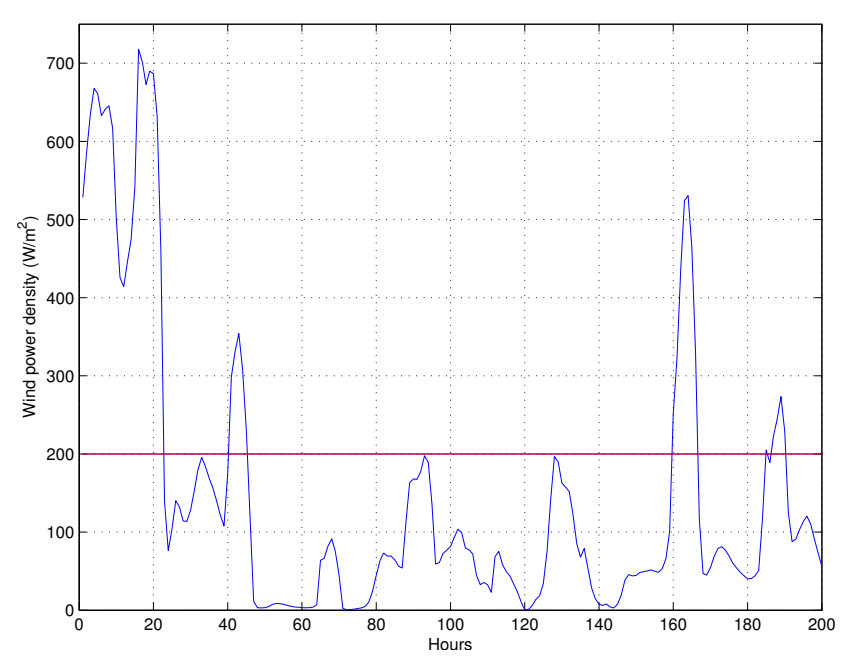

Fig. 1. Illustrative WPD profile showing the fluctuations in wind.

our estimates are more explicit and comprehensive in the analytic formalism. Conventionally, WPD is used as the physical quantity to describe the wind energy potential or the wind resource at a place. The US wind atlas (Elliott et al., 1987, 1991), for instance, maps the mean WPD over the contiguous states of the US To describe the quality of wind resource, it is proposed that more metrics of location and dispersion be taken into account. So, the median as another measure of location has been computed.

\subsubsection{Fluctuations}

In the aforementioned studies discussed in Sect. 1, all looked at mean WPD over the US Since a key objective of this study is the investigation of the fluctuations in WPD, fluctuations of two kinds are distinguished. Figure 1 shows the WPD for two hundred consecutive hours at a grid point in the central US This figure is used to define and differentiate two kinds of fluctuations.

According to the classification of WPD (WPD) into different classes (Table A1), $200 \mathrm{~W} \mathrm{~m}^{-2}$ is the upper bound for the class 1 , defined as the poor class. That is, if a location has WPD less than $200 \mathrm{~W} \mathrm{~m}^{-2}$, usable power cannot be produced. In the plot, the red line marks this lower limit of $200 \mathrm{~W} \mathrm{~m}^{-2}$.

For the initial $22 \mathrm{~h}$, there is usable WPD (above $200 \mathrm{~W} \mathrm{~m}^{-2}$ ) at this location but the value fluctuates from $\backsim 200 \mathrm{~W} \mathrm{~m}^{-2}$ to $\backsim 650 \mathrm{~W} \mathrm{~m}^{-2}$, then dips to $\backsim 400 \mathrm{~W} \mathrm{~m}^{-2}$, rises to slightly above $700 \mathrm{~W} \mathrm{~m}^{-2}$ and falls to less than $100 \mathrm{~W} \mathrm{~m}^{-2}$. So, although during this time, the turbine can produce useful power, the power produced fluctuates very much. For the sake of differentiation, this kind of fluctuation, herein, is termed variability.

Since power density less than $200 \mathrm{~W} \mathrm{~m}^{-2}$ is equivalent to no power, during the $200 \mathrm{~h}$ shown, there is power initially for $22 \mathrm{~h}$, then there is no power for $10 \mathrm{~h}$, then there is power 
for $\backsim 7 \mathrm{~h}$ and then, there is no power for $\backsim 110 \mathrm{~h}$ and so on. This phenomenon of switching between power and no-power states is, herein, termed intermittency.

\subsection{Intermittency metrics}

As mentioned, our analyses not only focus on characterizing the extent of wind power resource, but also its intermittent and variable behavior. As such, the following metrics are considered to investigate the intermittency of WPD.

1. Statistics of wind power episode lengths.

2. Statistics of no-wind power episode lengths.

3. Availability/unavailability of power density.

4. Probability distribution of wind episode lengths.

5. Probability distributions of no-wind episode lengths.

These metrics measure the persistence of wind power, or lack thereof, and it is generally acknowledged that persistence of WPD is important for reliability of power generation. Sigl et al. (1979) investigated the episode length distributions and developed a model for the episode length distributions based on a simple composite distribution. They showed that the shorter episode lengths obeyed a power law and the longer ones followed an exponential law. Following Sigl et al. (1979), the episode lengths in this study are modeled according to a composite distribution which is a mixture of a power law and an exponential law. The probability density function of this composite distribution is described by:

$f(n)=\left\{\begin{array}{lll}a t^{-b} & \text { if } & 0 \leq t \leq t_{1} \\ A \lambda e^{-\lambda t} & \text { if } & t_{1} \leq t \leq \infty\end{array}\right.$

where the first equation describes power law for episode lengths $t$ less than the partition parameter $t_{1}$ and the second equation is the exponential law for longer durations than $t_{1}$.

The episode lengths in hours are fitted to these distributions using the maximum likelihood estimation method. The parameters $a, b, A, \lambda$ are found for each location.

Run duration analysis is mostly used for estimating or predicting the performance of a future wind energy installation at the location. For greater persistence of wind power, the probability of the shorter runs should decrease and that of the longer ones should increase. In terms of the equation above, the power law factor should decrease and the exponential factor should increase.

The scaling factor, $a$, is the scaling factor in the power law that is applicable for the short duration run lengths. For the wind power to persist for longer durations, the probability of the short runs should fall very fast. So, for the locations that have this scaling factor $a$ low, the probability of shorter runs is low. The exponent, $b$, is the exponent in the power law.
So, if the $b$ is larger, because of the negativity in the exponent, the probability of the short runs is rendered small. Thus the median run length is longer. Similar to $a$, if $A$ is large, the probability of the longer runs increases. So, $A$ should be greater. For small values of $\lambda$, the probability curve described by exponential part of the above Eq. (7) has a shallower tail and hence the longer episodes have greater probability compared to the cases when the $\lambda$ is greater. As $\lambda$ increases, the probability of the shorter run lengths increases drastically.

For the discussion of the characteristics of WPD episode lengths in the next section, their statistics are computed from the WPD time series by explicitly counting the number of hours with WPD greater than $200 \mathrm{~W} \mathrm{~m}^{-2}$ and not from these distributions.

\section{Results and discussion}

\subsection{Descriptive statistics of wind power from MERRA wind}

\subsubsection{Mean and median WPD}

Figure 2 shows the mean WPD at the center of the surface across the US The Midwest region has power density in the range of $300-600 \mathrm{~W} \mathrm{~m}^{-2}$ whereas most of the regions flanking the Midwest on the east and west sides have WPD less than $200 \mathrm{~W} \mathrm{~m}^{-2}$ which is classified as poor. The offshore regions in the east and west have wind power densities in excess of $800 \mathrm{~W} \mathrm{~m}^{-2}$. Texas, Oklahoma, Kansas, Nebraska, Indiana, Minnesota, North Dakota and South Dakota - have WPD classified at least as fair and some pockets have "good" and "excellent" quality wind power densities corresponding to $400-500 \mathrm{~W} \mathrm{~m}^{-2}$ and $500-600 \mathrm{~W} \mathrm{~m}^{-2}$. The eastern half of Wyoming has the greatest onshore WPD of $500-800 \mathrm{~W} \mathrm{~m}^{-2}$. The offshore regions on the east and west coasts which are closer to the coastline have power densities of $\sim 700 \mathrm{~W} \mathrm{~m}^{-2}$ whereas the offshore region near northern California falls into the "outstanding" class with $1000 \mathrm{~W} \mathrm{~m}^{-2}$.

Figure 3 shows the median WPD at the center of the surface in $\mathrm{W} \mathrm{m}^{-2}$ across the US Comparing with the mean WPD in Fig. 2, the median values are almost half of the mean values. For any distribution, $50 \%$ of the values are below the median and $50 \%$ of the values are above the median. So, this figure implies that for at least $50 \%$ of the time, the mean WPD is less than half of the mean wind power density. Thus, we should regard the mean WPD as an overestimate to the true central tendency of this resource. Figure B1 shows the histogram of the wind power density at an illustrative point from the domain. Since the distribution is very skewed, the mean is not a robust measure of the center of this distribution. Given this long-tailed distribution, the very extreme values cause the deviation of the mean from the actual center of this distribution. We therefore view the median to be a more 


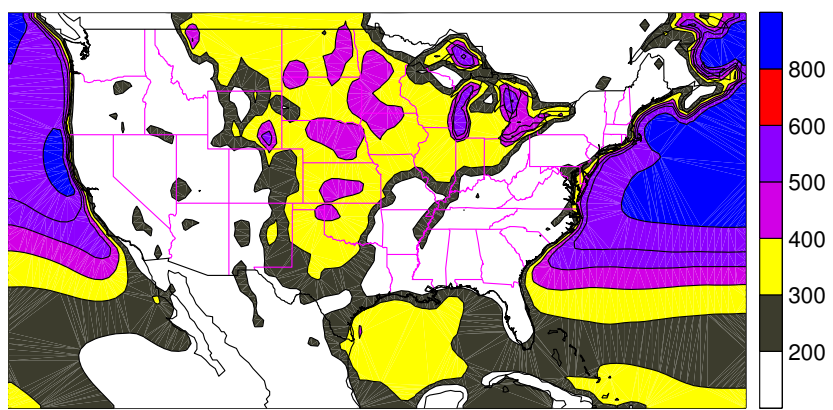

Fig. 2. Geographical variation of mean WPD $\left(\mathrm{W} \mathrm{m}^{-2}\right)$ across the US.

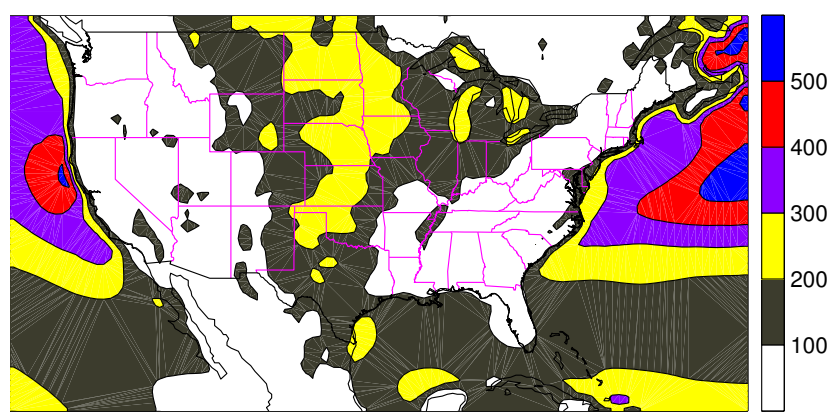

Fig. 3. Geographical variation of median WPD $\left(\mathrm{W} \mathrm{m}^{-2}\right)$ across the US.

robust indicator of central tendency and a more appropriate metric to represent WPD.

\subsubsection{Variability of the WPD}

The variability of a quantity is best captured in terms of coefficient of variation because it is desirable that the wind power is constant as much as possible. The robust coefficient of variation defined as:

$\mathrm{RCoV}=\frac{\text { median(absolute deviation about the median) }}{\text { median }}$

has been used to study the variability of WPD in different regions of the US.

For two regions with the same mean power density, the one with a lower median absolute deviation will have lower $\mathrm{RCoV}$ and is preferable (i.e. less variable power quality). Similarly, for two regions with the same median absolute deviation, the one with greater median wind power density is preferable and this has lower RCoV. Given the impact of variability in wind power on the electric grid and the economics of power generation and distribution, it is desirable to lay wind farms in regions of low $\mathrm{RCoV}$ of wind power. Figure 4 shows the robust coefficient of variation of WPD over the US.

Eastern and southwestern North Dakota, central and Southern Wisconsin, northwestern Illinois, Nebraska, southern Kansas and western Oklahoma have high mean WPD and

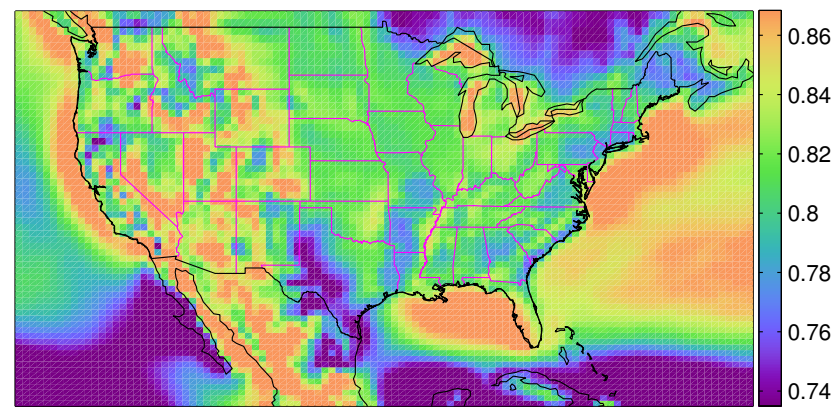

Fig. 4. Geographical variation of coefficient of variation of WPD across the US.

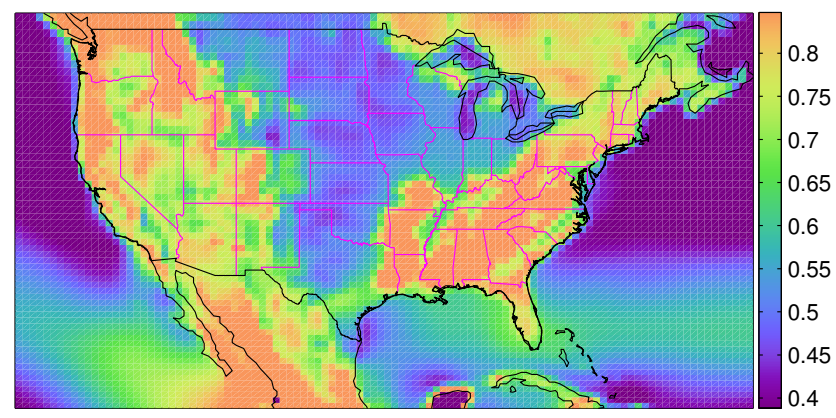

Fig. 5. Unavailability of WPD across the US.

moderate $\mathrm{RCoV}$. The near offshore regions have large $\mathrm{RCoV}$ and hence greater variability. The central US has an $\mathrm{RCoV}$ that is moderate. It is interesting that the western Gulf coast that has higher meanWPD has lower RCoV whereas the eastern Gulf coast that has lower mean WPD has greater variability as measured by RCoV. The Great Lakes region has the same variability as the offshore regions. Largely, the eastern half of the US has moderate $\mathrm{RCoV}$ whereas the western half of the US has slightly greater RCoV. Similar asymmetry is shown by the far offshore regions: Pacific has moderate $\mathrm{RCoV}$ and the Atlantic has greater RCoV implying greater variability.

Inter-quartile range (IQR) is a robust measure of statistical dispersion. The IQR shows the possible 'swings' of the WPD at a location. Thus it is a measure of the backup power that needs to be maintained. The central US region has an IQR of $300-600 \mathrm{~W} \mathrm{~m}^{-2}$ whereas for the rest of the continental US, the values are very low - below $200 \mathrm{~W} \mathrm{~m}^{-2}$. The noncentral US has a median WPD of $100 \mathrm{~W} \mathrm{~m}^{-2}$ and also the 75 th percentile is $200 \mathrm{~W} \mathrm{~m}^{-2}$ or less. Thus, this region has very low IQR. The offshore regions along the east and west coast have IQR $\backsim 700 \mathrm{~W} \mathrm{~m}^{-2}$ except the offshore region near northern California which has an IQR of $\backsim 1000 \mathrm{~W} \mathrm{~m}^{-2}$. It should be noted that this region also has greater mean WPD of about $\backsim 1000 \mathrm{~W} \mathrm{~m}^{-2}$. The far offshore Atlantic region on the east also has very large IQR $-\backsim 1000 \mathrm{~W} \mathrm{~m}^{-2}$. 


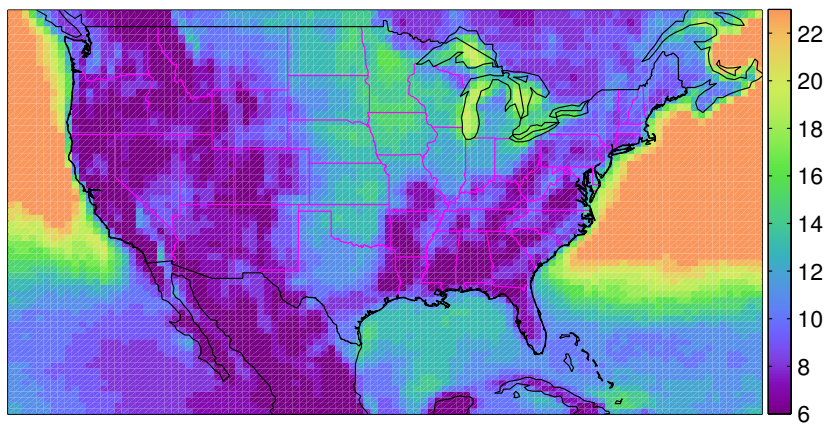

Fig. 6. Geographical variation of the median wind power episode length (h) across the US.

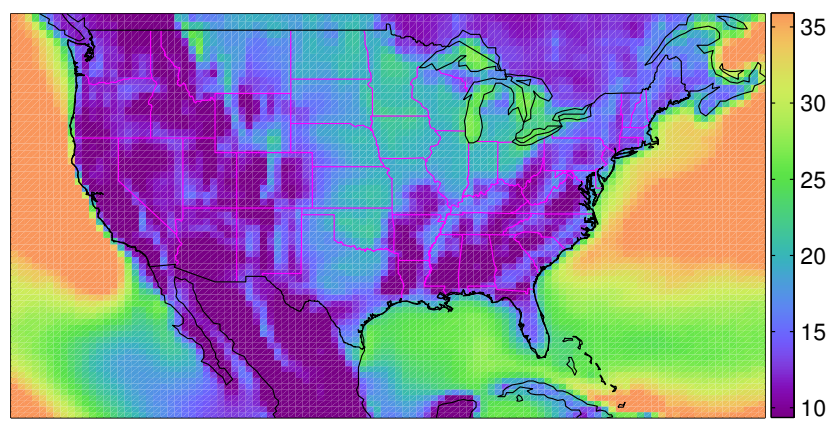

Fig. 7. Geographical variation of the mean wind power episode length (h) across the US.

\subsubsection{Availability of power}

In reliability theory, availability is a measure of the reliability of a system. Extending the concept to wind power, the availability of wind power at a location has been estimated as:

Availability $=\frac{\text { No. of hours with WPD } \geq 200 \mathrm{~W} \mathrm{~m}^{-2}}{\text { Total number of hours }}$

Figure 5 shows the unavailability, which is (1-availability), of wind power in the US The central US has the lowest unavailability onshore whereas most of the offshore region has the lowest unavailability of $40 \%$ or lower. The non-central US region has the greatest unavailability of $70 \%$ or more. This representation of wind resource is very important because it provides the temporal distribution of the resource.

\subsubsection{Wind episode lengths}

Episode lengths of WPD above $200 \mathrm{~W} \mathrm{~m}^{-2}$ are an important facet in understanding the persistence of the WPD and the nature of intermittency.

Figure 6 shows the median wind power episode lengths across the US The central US region has median episode lengths that range from 10 to $15 \mathrm{~h}$. Oklahoma, Kansas, Eastern Nebraska, Iowa and North Dakota have median episode lengths close to $15 \mathrm{~h}$ whereas the offshore regions on both

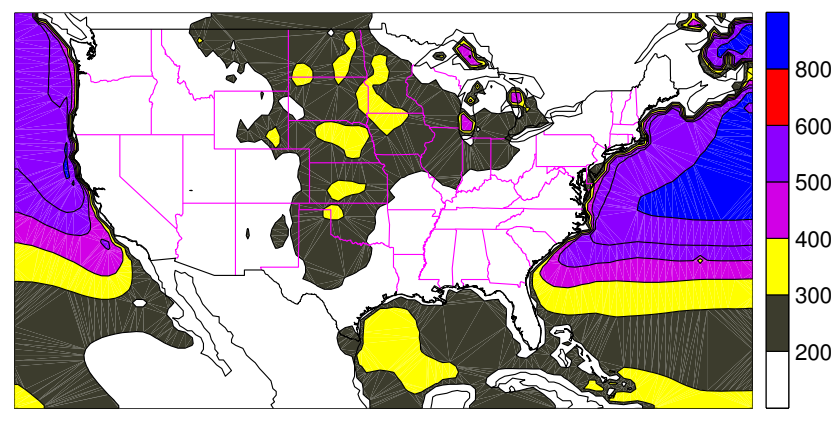

Fig. 8a. Geographical variation of the mean WPD $\left(\mathrm{W} \mathrm{m}^{-2}\right)$ at $50 \mathrm{~m}$ in the US.

sides of the US have long median episodes of $20 \mathrm{~h}$ or more. The non-central US states have very short median episodes of $10 \mathrm{~h}$ or less.

Figure 7 shows the geographical variation of the mean wind episode lengths across the US Comparing the median and mean values of episode lengths, while the central US has greater median episode lengths than some regions in West Virginia, Virginia, Louisiana, Mississippi, Alabama, Georgia, Tennessee, the latter regions have greater mean episode length. These states in the east and southeast have mean episode lengths as large as $120 \mathrm{~h}$. The consistency between mean and median values indicates that the wind episodes in the central US region are evenly distributed whereas in the southeastern states, the wind power is very steady only for isolated periods.

According to the reliability theory, the "time to repair" is an important metric of the reliability of a system. In wind power, it corresponds to the no-wind episode length, that is, the time for which the wind power is below the critical lower limit $\left(200 \mathrm{~W} \mathrm{~m}^{-2}\right)$ between two wind power episodes. The geographical variation of no-wind episode lengths is consistent with the mean and median episode length variation shown in the Figs. 7 and 6.

This knowledge of persistence of WPD should prove valuable in planning and developing a robust deployment strategy for harvesting wind power.

\section{WPD at different altitudes}

\subsection{Comparison with NREL map at $50 \mathrm{~m}$}

Comparison of the mean wind power density at $50 \mathrm{~m}$ height estimated in this study, Fig. 8a, and the estimate developed by NREL, Fig. 8b, shows that the regions with considerable wind resource - most of the midwest region viz. eastern Montana, North Dakota, South Dakota, eastern Wyoming, Nebraska, eastern Colorado, Kansas, Iowa, western Minnesota, the Gulf of Mexico coast of Texas, the Great Lakes - are all common features in both the estimates. The remainder of the US contains widespread areas of wind power 


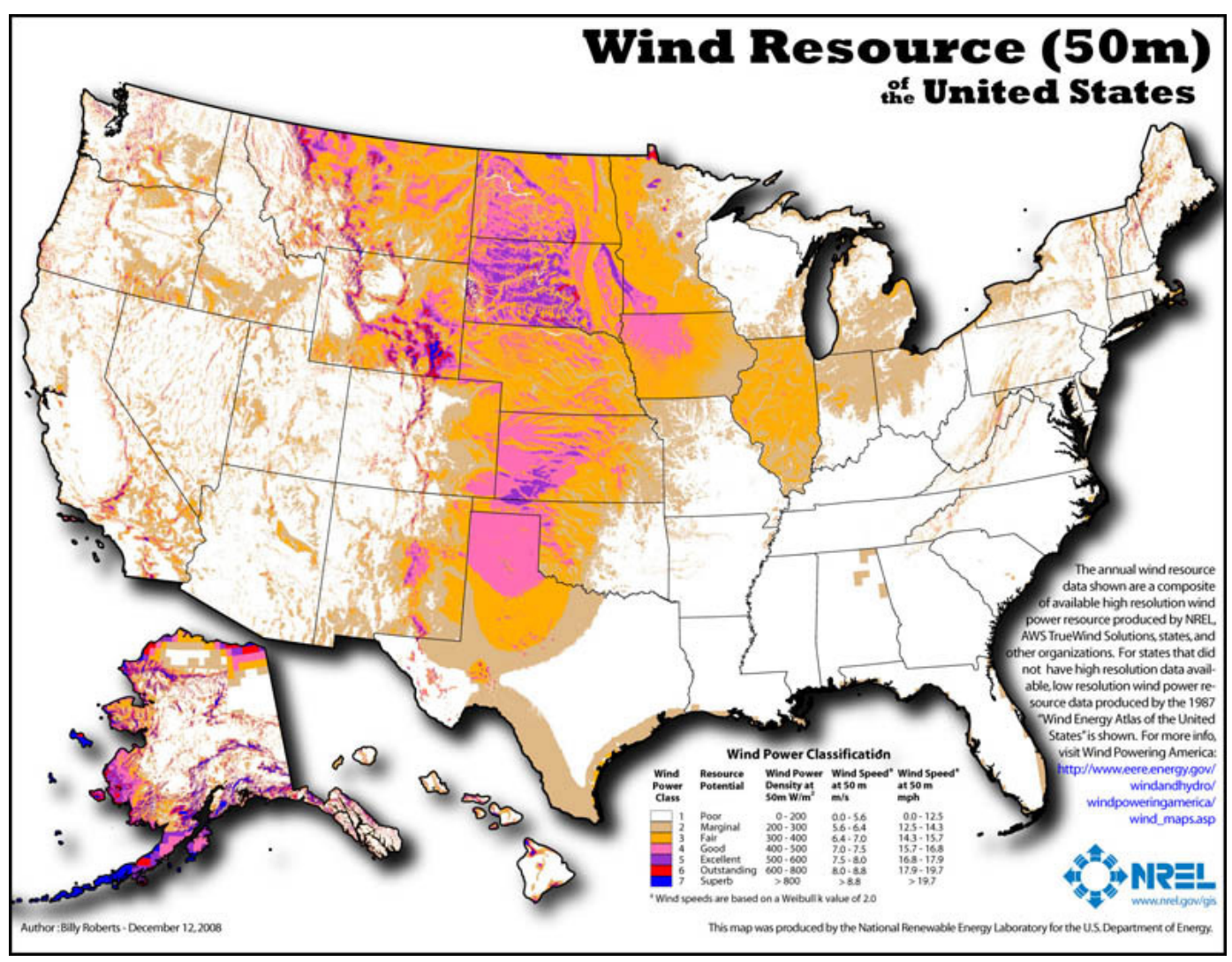

Fig. 8b. US WPD map at $50 \mathrm{~m}$ developed by NREL.

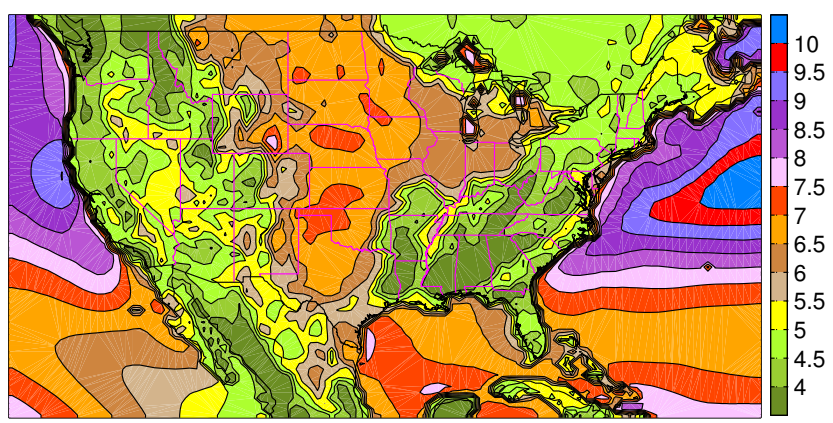

Fig. 9a. Geographical variation of the mean wind at $80 \mathrm{~m}$ in the US The white-shaded regions have annual mean wind speeds that are less than or equal to $4 \mathrm{~ms}^{-1}$.

density that corresponds to the 'poor' class (Class 1). Thus the wind resource estimation using the MERRA dataset is qualitatively similar to the wind resource at $50 \mathrm{~m}$ estimated by Elliott et al. $(1987,1991)$ for NREL.

Further, Elliott et al. (1987), based on the three criteria abundance and quality of the observational data used to estimate the wind speed, the complexity of the terrain and the geographical variability of the resource - described the confidence in the wind resource estimate using certainty rating from 1 to 4,1 being highly uncertain and 4 being very un- certain. In regions where the certainty rating is 1 , the actual WPD may vary by a few wind power classes. When these certainty ratings are taken into consideration, the WPD estimated at $50 \mathrm{~m}$ is well within the bounds of uncertainty.

Justus et al. (1976) observed that across the US, the shape parameter for Weibull distribution of wind speeds varies between 1.1 and 2.7 and the mean value is 2.0. As discussed above, a larger shape parameter is used for larger wind speed regions. Note also that a unit of difference in wind speed corresponds to greater change in WPD for the larger wind speed region than the lower wind speed regions. Thus, in addition to the uncertainty in the data, the Weibull-fitted estimate may be prone to systematic overestimations in regions of greater resource, for instance in the Midwest.

\subsection{Comparison of wind speed at $80 \mathrm{~m}$ with the NREL map}

Figure 9a shows the mean wind speed at $80 \mathrm{~m}$ developed in this study. The figure shows the wind speed from $4 \mathrm{~ms}^{-1}$ to $10 \mathrm{~ms}^{-1}$. Figure $9 \mathrm{~b}$ shows the estimates of annual mean wind speed at $80 \mathrm{~m}$ height developed by AWS Truepower NREL (2010). A mesoscale model, MASS, was run at a higher resolution with boundary conditions from NCEP Reanalysis. The simulated winds were downscaled using a statistical model to 


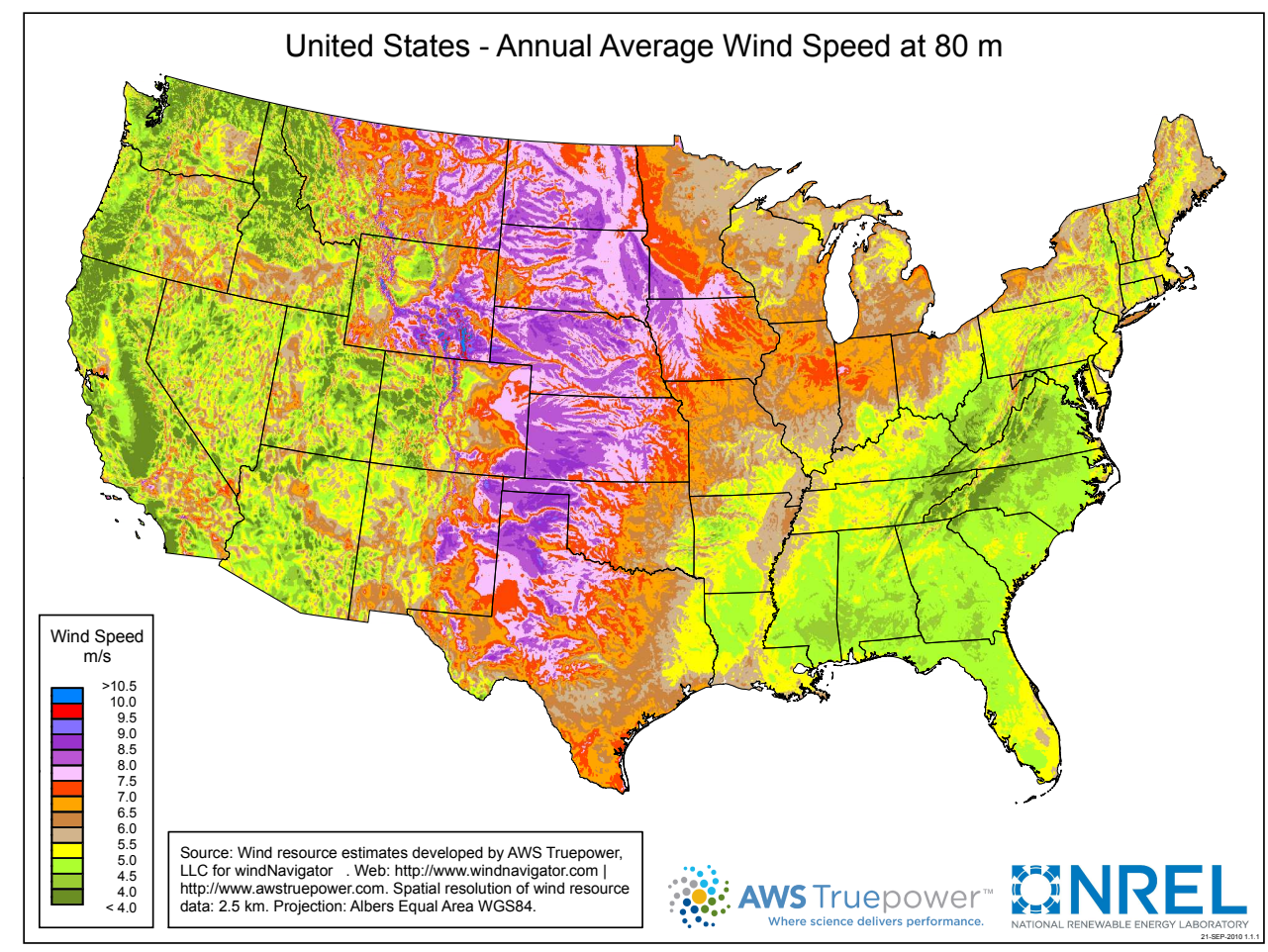

Fig. 9b. US wind map at $80 \mathrm{~m}$ developed by NREL.

a resolution of $50 \mathrm{~m} \times 50 \mathrm{~m}$. The figure shows the mean wind speed from $4 \mathrm{~ms}^{-1}$ to $10.5 \mathrm{~ms}^{-1}$ with $0.5 \mathrm{~ms}^{-1}$ interval.

Remarkably, the two figures match very well qualitatively and also are very close in their geographical variation. For example, the central US region consisting approximately of eastern New Mexico, northern Texas, western Oklahoma, Kansas, Nebraska, South Dakota, North Dakota, western Iowa, southwestern Minnesota, eastern Montana, eastern and southeastern Wyoming have wind speeds between $7 \mathrm{~ms}^{-1}$ and $8.5 \mathrm{~ms}^{-1}$. Wisconsin, eastern Minnesota, eastern Iowa, Illinois, northern Indiana and Ohio, large parts of Texas and, Missouri and Michigan have wind speeds roughly between $5.5 \mathrm{~ms}^{-1}$ and $7.0 \mathrm{~ms}^{-1}$.

The eastern region of Florida has a mean wind speed of $5 \mathrm{~ms}^{-1}$, whereas a large tract of land covering northern Florida, Georgia, South Carolina, North Carolina, Alabama, a large part of Mississippi, Kentucky, Tennessee, Virginia, West Virginia, southern Ohio, southeastern New York, New Jersey, Connecticut, non-coastal Massachusetts, New Hampshire, Vermont and western Maine have wind speeds in the lower end of the spectrum below $5.5 \mathrm{~ms}^{-1}$.

On the west side, most of the regions have low wind speeds except the mountainous stretches. Some small patches of regions in southern California, western Utah, central Arizona, southwest New Mexico, southwest Wyoming, southeast Ore- gon, southwest Idaho, and southwest Washington have considerable wind speeds between $6.0 \mathrm{~ms}^{-1}$ and $7.5 \mathrm{~ms}^{-1}$.

Although the NREL estimate is at a higher resolution of $2.5 \mathrm{~km}$ compared to $1 / 2^{\circ}$ in this estimate, this estimate compares very well with the NREL estimate in almost all regions. There are some small regions in the central US where the NREL estimate shows wind speeds of $8.5 \mathrm{~ms}^{-1}$ and greater which this estimate misses because of the lower resolution.

Archer and Jacobson (2003, 2007) used measurements from surface stations and soundings and extrapolated winds at $10 \mathrm{~m}$ to $80 \mathrm{~m}$ assuming a power law profile. The measurement data was for the year 2000. The wind speed estimates at $80 \mathrm{~m}$ in this study are largely similar to the estimates by Archer and Jacobson (2003, 2007).

\subsection{WPD at different hub heights}

With the confidence gained out of the close match of the two estimates as described above, we now look at the effect of raising the altitude on the different metrics and quality of the wind resource.

To complete the picture of wind resource, in addition to the description of wind speeds, we discuss WPD variation across the US Fig. 10 shows the mean WPD for an $80 \mathrm{~m}$ hub 


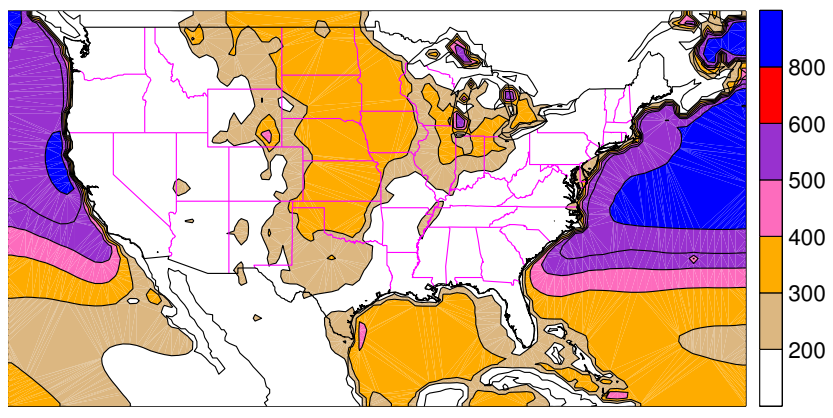

Fig. 10. Geographical variation of the mean WPD at $80 \mathrm{~m}$ $\left(\mathrm{W} \mathrm{m}^{-2}\right)$.

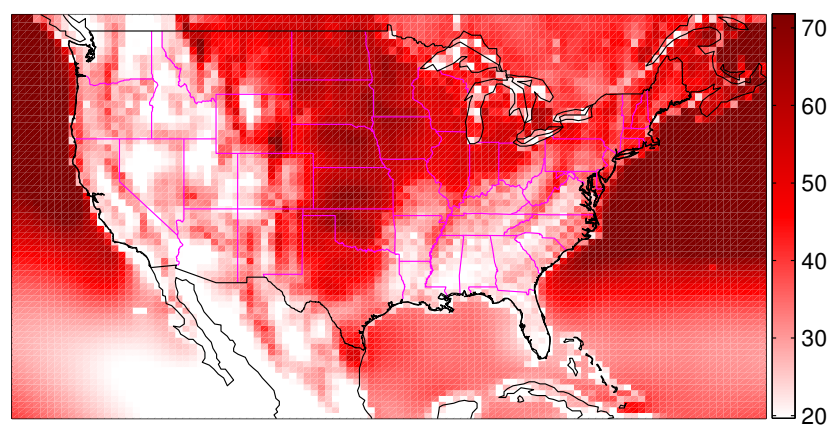

Fig. 11. Difference mean WPD between $80 \mathrm{~m}$ and $50 \mathrm{~m}\left(\mathrm{~W} \mathrm{~m}^{-2}\right)$.

height in the contiguous US and over the off-shore regions on both sides of the US.

The central US consisting of the areas from north Texas in the south, Oklahoma, Kansas, Nebraska, South Dakota to North Dakota and the regions around the Great Lakes northeastern Illinois, eastern Wisconsin, northern Indiana, southern Michigan, and northwest Ohio - are regions of high resource, generally in the range of $300-400 \mathrm{~W} \mathrm{~m}^{-2}$. The southwest region of Wyoming has the greatest inland WPD of $400-500 \mathrm{~W} \mathrm{~m}^{-2}$.

Even though the mountainous regions on the west coast have high wind speeds, as can be seen in Fig. 9a, those regions have low WPD (Fig. 10). Similarly, the wind speeds on the Appalachians are high but the WPD is low. This is a result of the lower density of air on these high altitude regions. The air density and altitude of a location are related as:

$\rho=1.225-\left(1.19 \times 10^{-4} \times z\right)$

This Eq. (9) shows that a difference in altitude of $2000 \mathrm{~m}$ makes a difference of about $20 \%$ in the mean WPD. Further, it also erroneously characterizes the mountainous regions as high wind resource locations. Thus, wind speed is not a suitable measure for the wind resource. If WPD is used, it is more comprehensive as it covers the variation of air density.

Although the coastal states have very poor wind resource, the offshore regions abutting the coast have high wind re- source. Particularly, the coasts of Connecticut, Rhode Island, Massachusetts and Maine have WPD of $600-700 \mathrm{~W} \mathrm{~m}^{-2}$. Similarly, the offshore region near the coast of northern California also has very high resource in the range of 700$800 \mathrm{~W} \mathrm{~m}^{-2}$. The Gulf of Mexico region also has appreciable wind resource of $300-400 \mathrm{~W} \mathrm{~m}^{-2}$ although it is in general less than the offshore WPD on the east and west coasts.

Figure 11 shows the difference in mean wind power density between $80 \mathrm{~m}$ and $50 \mathrm{~m}$. Clearly, in general, there is an increase in the quantity as the height is raised. The increase is higher in the central US region and in the New England region, along the Appalachian mountain region, New Jersey, New York and some regions of Pennsylvania.

Intuitively, the change is dependent on the wind resource at the lower level and the roughness length. In regions where the resource is high at the lower level, even a small gradient in the vertical profile would mean an appreciable increase at the upper level. Also, in regions which have high surface roughness length, the wind profile has a sharper gradient and so, even a smaller wind speed at the lower level may mean an appreciable increase in the wind speed at the upper level. Thus, the greatest advantage of raising the altitude is in regions that have higher surface roughness length, for instance due to vegetation, and also in regions that have higher resource at the lower level.

Another important reason for the large increase in the central US is the presence of a strong nocturnal low level jet that has a maximum between $500 \mathrm{~m}$ and $800 \mathrm{~m}$. This low level jet induces a gradient in the vertical wind profile that is considerable and is maximum at 06:00 in the morning. Schwartz and Elliot (2005) measured the wind speed using towers fitted with anemometers at several sites in the central US as a part of wind resource assessment at higher altitudes. They reasoned that the nocturnal jet is an important cause of the increase in wind resource at night in these regions.

As discussed above, the hub height of most wind turbines installed in the last decade is $80 \mathrm{~m}$. Therefore, in the subsequent sections, the wind resource, its variation and intermittent character is discussed accordingly.

As discussed above, there is a general increase in the resource as the altitude is increased. As the hub height is increased, the mean WPD increases fast initially and with further rise in height, the increase in the mean resource is less. Although increase in the mean wind resource decreases, there does not seem to be a saturation in the benefit even with reasonable increase in hub heights beyond the present $100 \mathrm{~m}$ and $120 \mathrm{~m}$.

It was argued that both mean and median should be used to describe the wind resource. Figure 12a shows the geographical distribution of median WPD at $80 \mathrm{~m}$. It shows that most of the central US has median WPD ranging between $100 \mathrm{~W} \mathrm{~m}^{-2}$ and $200 \mathrm{~W} \mathrm{~m}^{-2}$. As the height is increased from $80 \mathrm{~m}$ to $120 \mathrm{~m}$, the median increases (Figs. $12 \mathrm{~b}$ and c). That is, frequencies of higher wind power densities than those of 

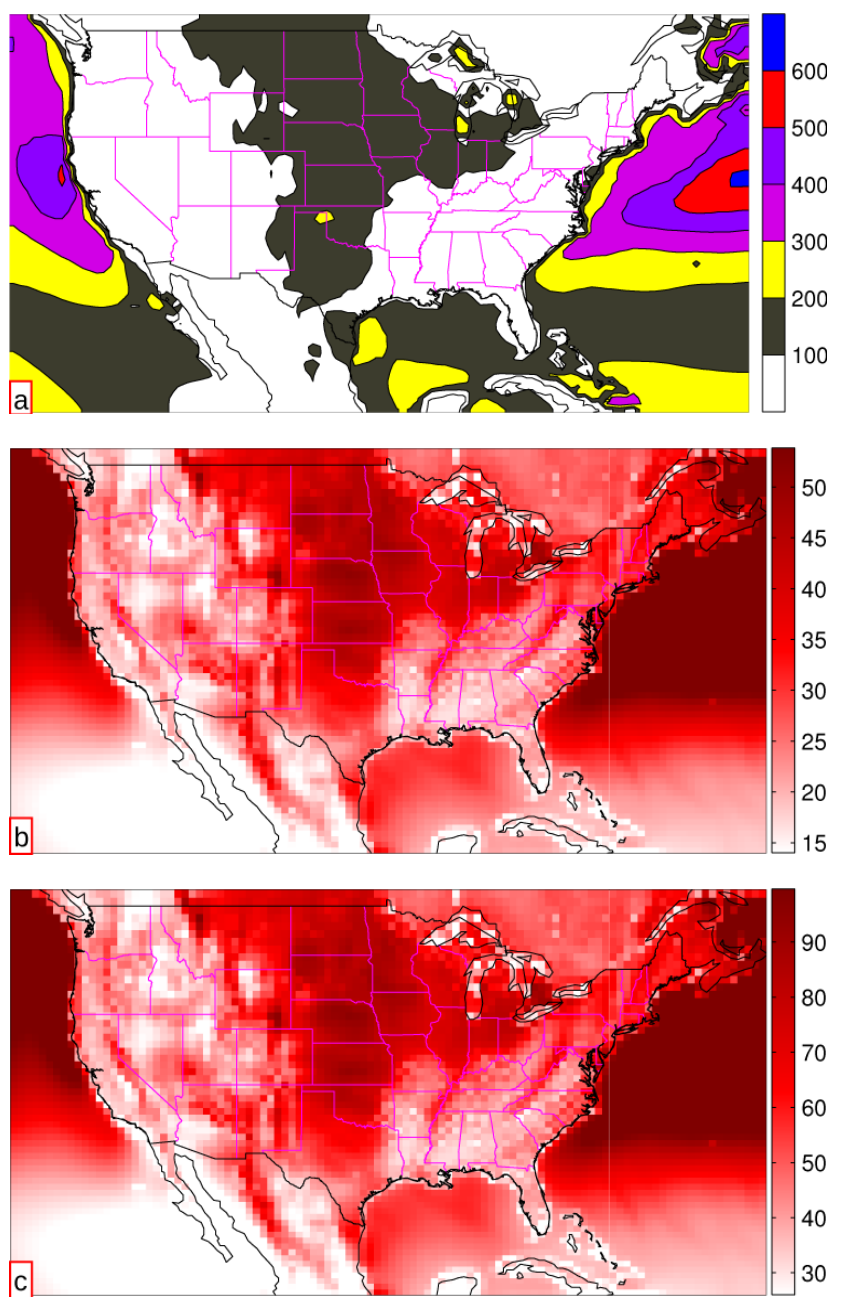

Fig. 12. Variation of median WPD $\left(\mathrm{W} \mathrm{m}^{-2}\right)$ at different heights. (a) shows the median wind power at $80 \mathrm{~m}$ and, (b) and (c) show the difference median WPD at $100 \mathrm{~m}$ and $120 \mathrm{~m}$ from that at $80 \mathrm{~m}$.

the the median at $80 \mathrm{~m}$ increase. But similar to the mean resource, the increase in median WPD decreases with altitude.

Schwartz and Elliot (2005) found that the shear exponent for vertical adjustment of wind speed is considerably greater than the conventionally used $1 / 7$. Also, they reported that the windy sites, for instance those in the central US, have lower $\alpha$ s than the less windy sites. Thus, the increase in the mean and median WPD in the central US, and the less windy sites like the New England region, may be the same because of the higher shear exponent in the less windy regions. Thus the altitude variation shown in these Fig. $12 \mathrm{~b}$ and $\mathrm{c}$ are consistent with the recent measurements and the patterns of vertical variation.

Because the mean wind resource increases with altitude, as seen in the previous subsection, it implies that the frequency distribution of the wind power density shifts to the right. Also, the frequency distribution is broadened. Thus, the inter-quartile range increases with height, but the increase
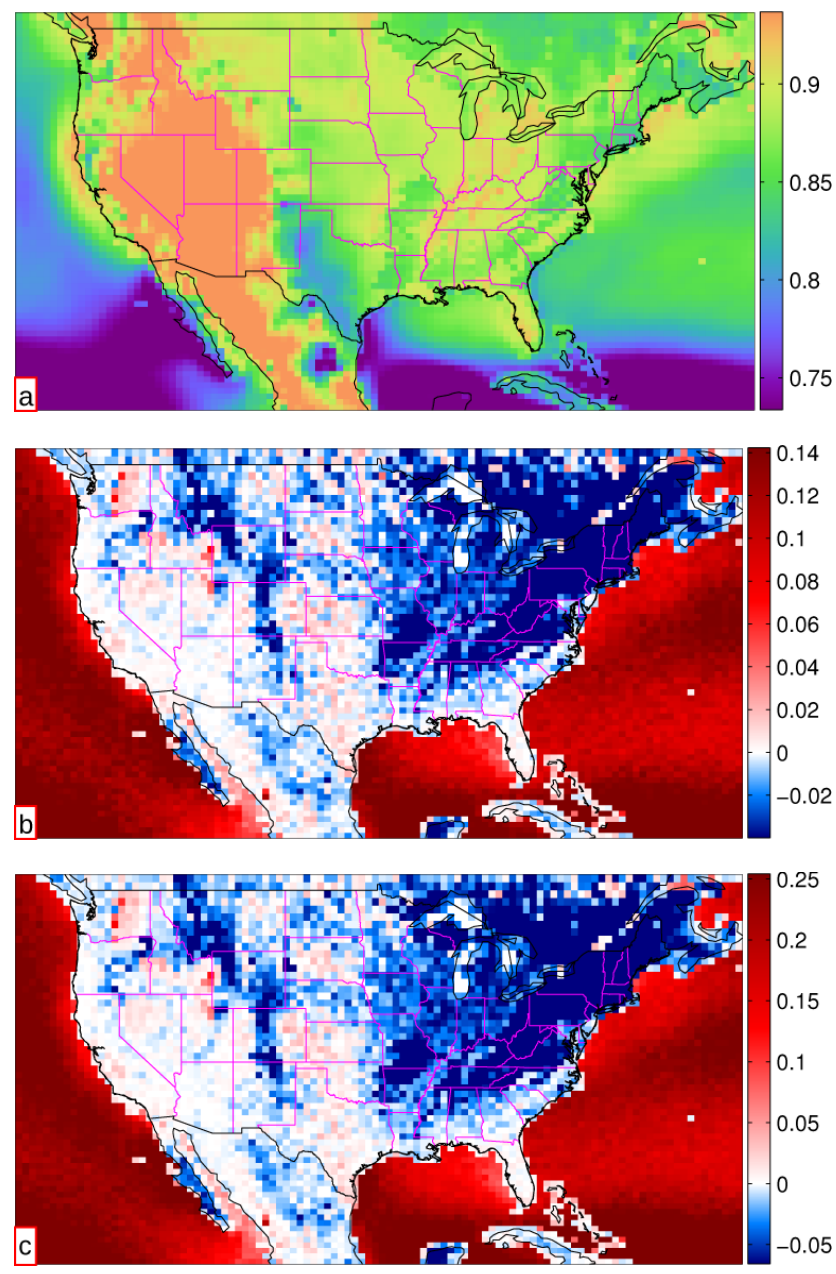

Fig. 13. Variation of the coefficient of variation of WPD at different heights. (a) shows the RCoV of WPD at $80 \mathrm{~m}$ and (b) and (c) show the difference RCoV of WPD at $100 \mathrm{~m}$ and $120 \mathrm{~m}$ from that at $80 \mathrm{~m}$.

diminishes with height. Going from $80 \mathrm{~m}$ to $100 \mathrm{~m}$, the interquartile range increases by half a class in the central US, whereas in the offshore regions the increase is larger. Raising the turbine hub height from $80 \mathrm{~m}$ to $120 \mathrm{~m}$ results in more than a class of increase in the wind resource quality.

Coefficient of variation describes the variability of a quantity globally. Figure 13 shows the variation of RCoV across the US Fig. 13b and c are the differences in RCoV at $100 \mathrm{~m}$ and $120 \mathrm{~m}$ from that at $80 \mathrm{~m}$. It is interesting to note that while the RCoV decreases over land, it increases slightly over the oceans. This is because the wind resource increases in general and by a large amount over the ocean. The RCoV decreases with increasing mean for a steady standard deviation. Thus, this phenomenon means that the variance in the offshore regions increases much more than the mean. An important implication of this phenomenon is that the back-up required to compensate the variability in the wind power is greater. 
Another interesting feature of the difference plots is that the RCoV decreased in the northeastern states of Maine, Vermont, New Hampshire, New York, New Jersey, Pennsylvania, West Virginia and southern Ohio. Thus, the largest increase in persistence of wind power with altitude is in these northeastern states. The distribution of the wind power episode lengths are important in estimating and planning the back-up requirements. Thus, the knowledge of the changes in the statistical behavior of episode lengths at different heights may help in planning the utilization of the wind resource at a location or the enhancement of existing deployment facilities with higher turbines.

The geographical distribution of the mean wind episode length at $80 \mathrm{~m}$ shows great variation between $6 \mathrm{~h}$ to $38 \mathrm{~h}$. The central US and the offshore regions have longer WPD episodes whereas teh rest of the inland areas have shorter WPD episodes. The Gulf of Mexico and the Gulf coast too have longer mean WPD episodes, more than that in the central US. Thus, it is possible that these regions have very highly consistent wind power resource due to cyclonic activity in the Gulf of Mexico. The moderate episode lengths of the central US are due to the stong diurnal cycle in these regions. Thus, the episode length in these regions is very predictable compared to the regions where the episode length is very low or very high.

A similar picture is shown by the median WPD episode length at $80 \mathrm{~m}$, shown in Fig. 15. For the non-central US region, the mean and median values are close. The central US and the offshore regions have greater median values than the rest of the areas. The two figures also show that as the mean and median episode lengths increase, the distributions of the episode lengths are positively skewed.

Figure $15 b$ and $c$ show the geographical variation of the mean wind episode lengths at $100 \mathrm{~m}$ and $120 \mathrm{~m}$ compared to the mean WPD episode lengths at $80 \mathrm{~m}$. It is interesting to see that the mean wind episode increases everywhere except the mountaineous region in the west. Further, like in the case of the other measures, the change in mean wind episode length also slowed down with height.

It is interesting that teh greatest change in mean episode lengths in the continental US is in the northeast and easter US. Because of the greater roughness length of this region, wind speeds increase with height resulting in longer episodes. Thus, these regions benefit the most due to increase in hub heights.

While geographic patterns are discerneable in mean episode lengths, patterns are not clean until $120 \mathrm{~m}$ in the case of the median episode lengths. The difference median episode length plots seem to show random variation. The reason for this appearance is that median is a rank statistic and so, the difference is an integer number of $\mathrm{h}(1 \mathrm{~h}$ or $0 \mathrm{~h}$ in the present plots) and in cases of even number of episodes, a $0.5 \mathrm{~h}$ difference in red color is seen at some points.

But at $120 \mathrm{~m}$, the pattern clearly emerges that in the northeast, east coast, in some regions in the central US and in Cal-
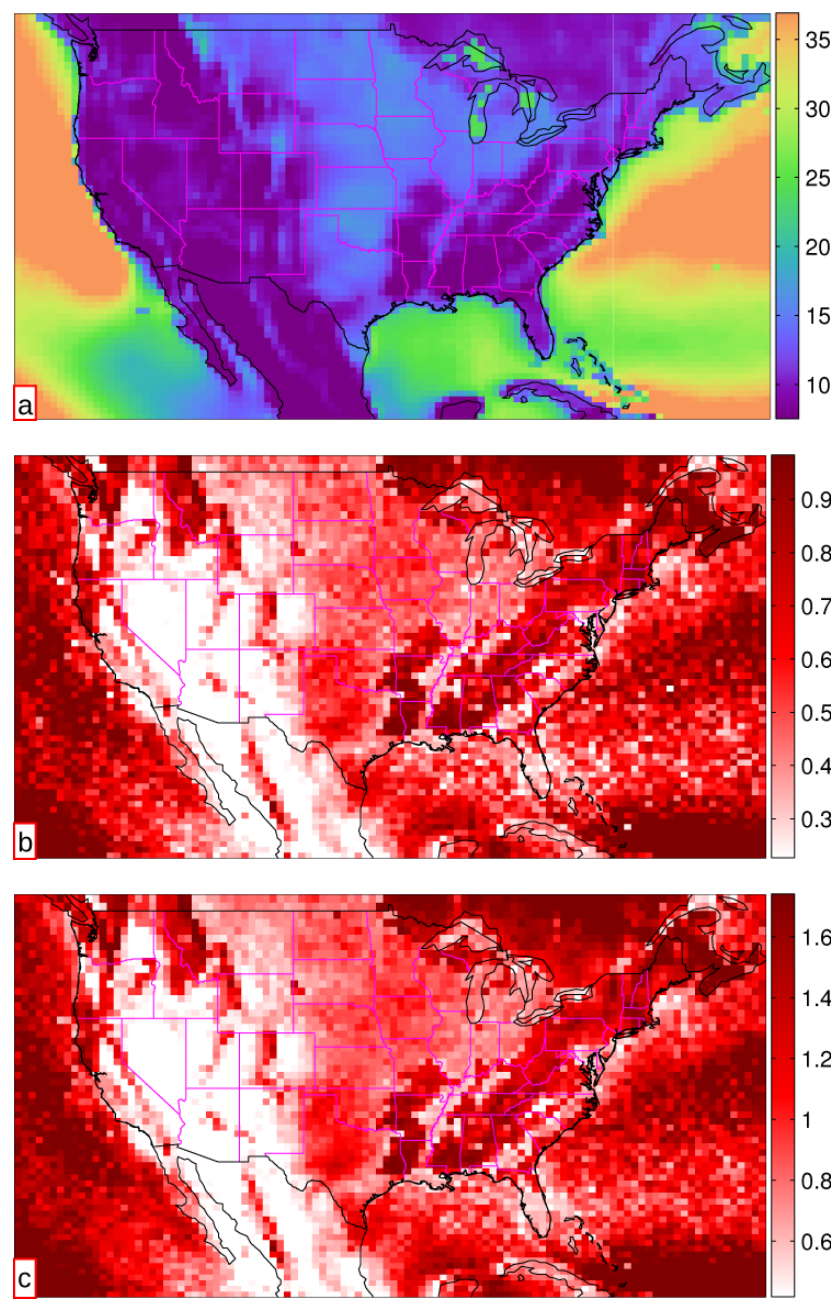

Fig. 14. Variation of mean WPD episode lengths (h) at different heights. (a) shows mean wind power episode length at $80 \mathrm{~m}$ and, (b) and (c) show the difference WPD episode length at $100 \mathrm{~m}$ and $120 \mathrm{~m}$ from that at $80 \mathrm{~m}$.

ifornia, the median increases by an hour. Thus, these regions benefit the most in terms of raising the turbine hub height.

Robust coefficient of variation of WPD episode lengths at $80 \mathrm{~m}$ is shown in Fig. 16. The central US region consisting of Montana, North Dakota, South Dakota, Nebraska, Kansas, Oklahoma and northern and southeast Texas, Iowa and Wisconsin have higher variability in episode lengths compared to the rest of the inland USA. The offshore regions have the greatest variability in episode lengths.

Figure $16 \mathrm{~b}$ and $\mathrm{c}$ show the change in the robust coefficient of variation of the episode lengths as the hub height is raised to $100 \mathrm{~m}$ and $120 \mathrm{~m}$ respectively. The lack of geographical patterns at $100 \mathrm{~m}$ and their presence at the $120 \mathrm{~m}$ atlitude are explained by the fact that robust coefficient of variation is a rank statistic. The evoloving patterns at $120 \mathrm{~m}$ show increases and decreases in variability of episode lengths and the difference in variability from that at $80 \mathrm{~m}$ is negligible. 

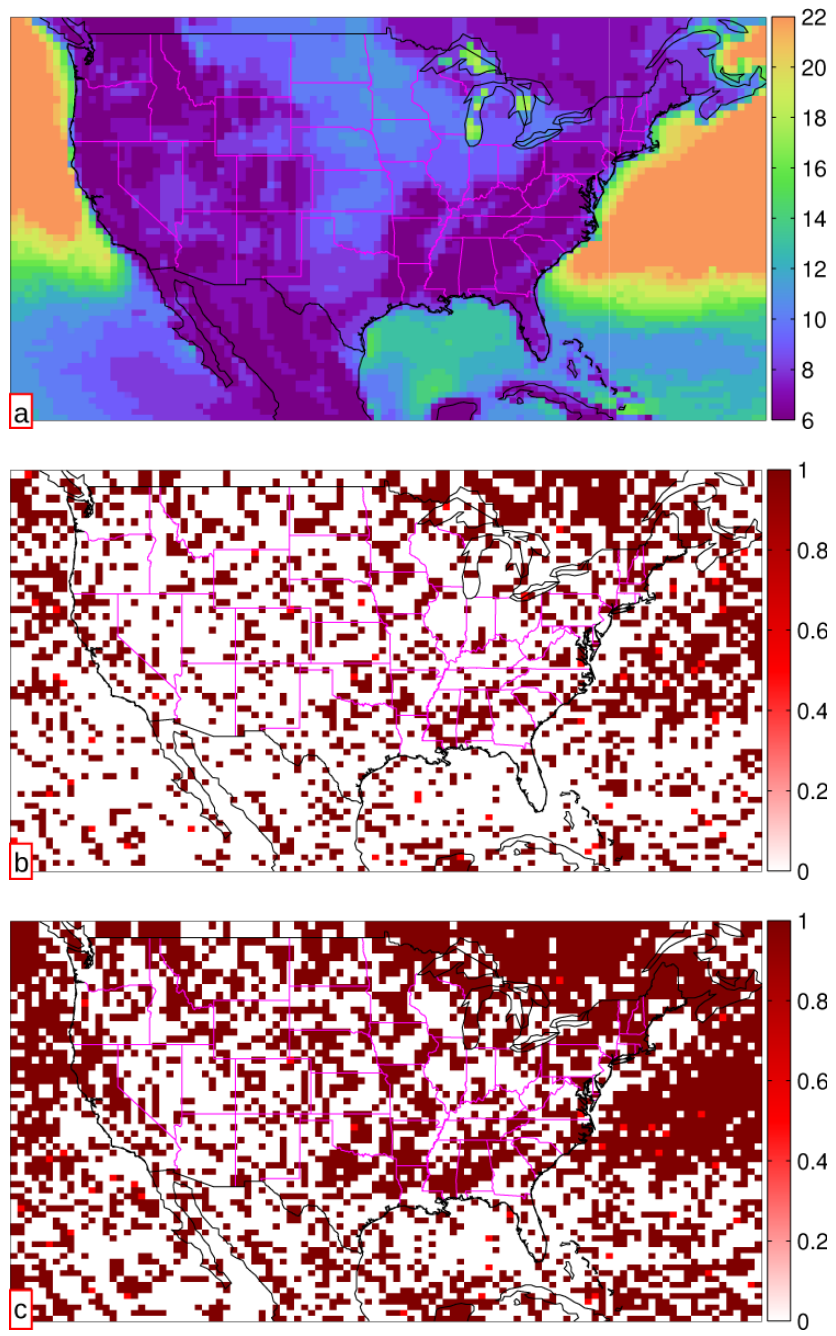

Fig. 15. Geographical variation of the median wind power episode length (h) at different heights. (a) shows median wind power episode length at $(80 \mathrm{~m})$ and, (b) and (c) show the difference WPD episode length at $100 \mathrm{~m}$ and $120 \mathrm{~m}$ from that at $80 \mathrm{~m}$

\section{Conclusions}

\subsection{Limitations and key assumptions}

Before summarizing the results and inferences of our study, we note the key assumptions and limitations of the study.

1. The data used for construction of the wind resource is a result of the assimilation of measurement and satellite remote sensed data into a global model. Thus the imperfections of the model and the assimilation schemes are bound to influence the computed output.

2. The assumption that the atmosphere is neutrally stable may not hold when the buoyancy fluxes dominate in the afternoons (the atmosphere is unstable) or at nights when the atmosphere is highly stable. Thus uncertain- ties in the estimates of WPD are possible under very unstable or very stable conditions.

3. The spatial resolution of the data is $0.5^{\circ} \times 0.67^{\circ}$ and the temporal resolution is one hour. So, some local effects that change wind speeds like mountain passes and valleys are not represented in this study. Further, since the time resolution is an hour, intermittency and other phenomena of higher scale and their effects can only be studied.

4. It is assumed that all the wind resource that is available is harnessed.

5. While studying the variation of wind resource the demand or load and the economic feasibility are not taken into consideration.

6. Magnitudes of some of the results are dependent on the minimum WPD threshold $\left(200 \mathrm{~W} \mathrm{~m}^{-2}\right)$. But qualitatively, the results are very robust as a lower threshold $\left(140 \mathrm{~W} \mathrm{~m}^{-2}\right)$ produced the same qualitative results.

\subsection{WPD at the surface}

We have undertaken an assessment of the wind power resource for the US WPD time series at each grid point in the domain between $20^{\circ}$ and $50^{\circ} \mathrm{N}$, and $130^{\circ}$ and $60^{\circ} \mathrm{W}$ has been constructed using the MERRA atmospheric reanalysis which has a spatial resolution of $0.5^{\circ} \times 0.67^{\circ}$ and hourly time resolution for the period 1979-2009. The effective wind speed at the center of the surface from the reanalysis has been used for this purpose. This dataset has been used to study and characterize the quality of onshore wind resource across the US and our analysis has also considered offshore regions. The constructed mean WPD map shows the established qualitative abundance of wind resource across the US The median wind power densities are approximately half of the mean values. Thus, for substatially more than $50 \%$ of the time, the WPD at a place is less than half of the mean WPD.

Conventionally, wind resource has been summarized in terms of the mean wind speed or the mean WPD at a location. Since the mean wind speed does not include the effects of variations in density, the mean wind speed does not comprehensively represent the wind resource at a location. Also, the wind atlases produced by the energy agencies of many countries represent the wind resource in terms of the mean WPD. Although WPD is a good variable to encompass the effects of wind speed and air density simultaneously, our results indicated that the mean as a central tendency overestimates the resource as can be seen from the frequency distribution of WPD which is a positively skewed and long tailed distribution. Thus, to more accurately represent this distribution, median should be used. The variability of the wind resource as measured by the coefficient of variation shows that, usually, the regions with higher wind resource have higher variability. But among those regions, the Atlantic offshore region has 
greater variability than the central US region. Unavailability of wind resource, as a measure of the reliability of the system, has been mapped as the number of hours with no usable WPD at a location. The map shows that the central US has the lowest unavailability and the offshore regions have unavailability of $40 \%$ or lower.

Maps of statistics of the wind and no-wind episode lengths have been developed for the US region. They help in understanding the persistence characteristics of WPD and the lumped nature of intermittency. The maps of median and mean episode lengths show that for the central and noncentral US, the distributions of wind episode lengths have distributions that are differently skewed. The wind episodes in the central US are symmetrically distributed where as in the southeastern states, the wind power is very steady for some periods. Such knowledge of steadiness of WPD is very helpful in planning the development of wind power harnessing.

\section{$5.3 \quad$ Altitude dependence of WPD}

The boundary layer flux parameters friction velocity, surface aerodynamic roughness length and displacement height - and the similarity theory of boundary layer dynamics have been used to estimate the wind speed at different wind turbine hub heights $-50 \mathrm{~m}, 80 \mathrm{~m}, 100 \mathrm{~m}$ and $120 \mathrm{~m}$ - and the variation of the wind resource and its characteristics have been studied with respect to altitude. Since time varying parameters have been used in our estimation, they are likely to be more robust than those in the studies that used a logarithmic law or a power law with empirically determined exponents. Comparison of the WPD at $50 \mathrm{~m}$ constructed in this study and that developed by NREL shows that the regions of appreciable wind source are similar in both the estimates. But there are some quantitative differences. Taking into account the uncertainty rating of the estimates in different regions in the NREL atlas, our estimates fall well within the bounds of the uncertainty estimates of the NREL atlas.

For the wind resource at $80 \mathrm{~m}$, comparison of mean wind speed at $80 \mathrm{~m}$ estimated in this study and that estimated by NREL shows that both the estimates are very close qualitatively and also quantitatively. There are a few patches of regions in the central US where NREL estimates show wind speeds greater than $8.5 \mathrm{~ms}^{-1}$ which this estimate misses because of slightly lower resolution than the NREL study. To complete the picture, mean WPD at $80 \mathrm{~m}$ has been examined (although a direct comparison with the NREL study was not possible). The central US and offshore regions (especially off the coast of New England and central California) show the greatest potential. An interesting fact that this plot shows is that even though the mountainous regions on the west coast have high wind speeds, these regions have low WPD because of the lower air density. This also shows that mean wind speed can not be a reliable measure of wind resource.
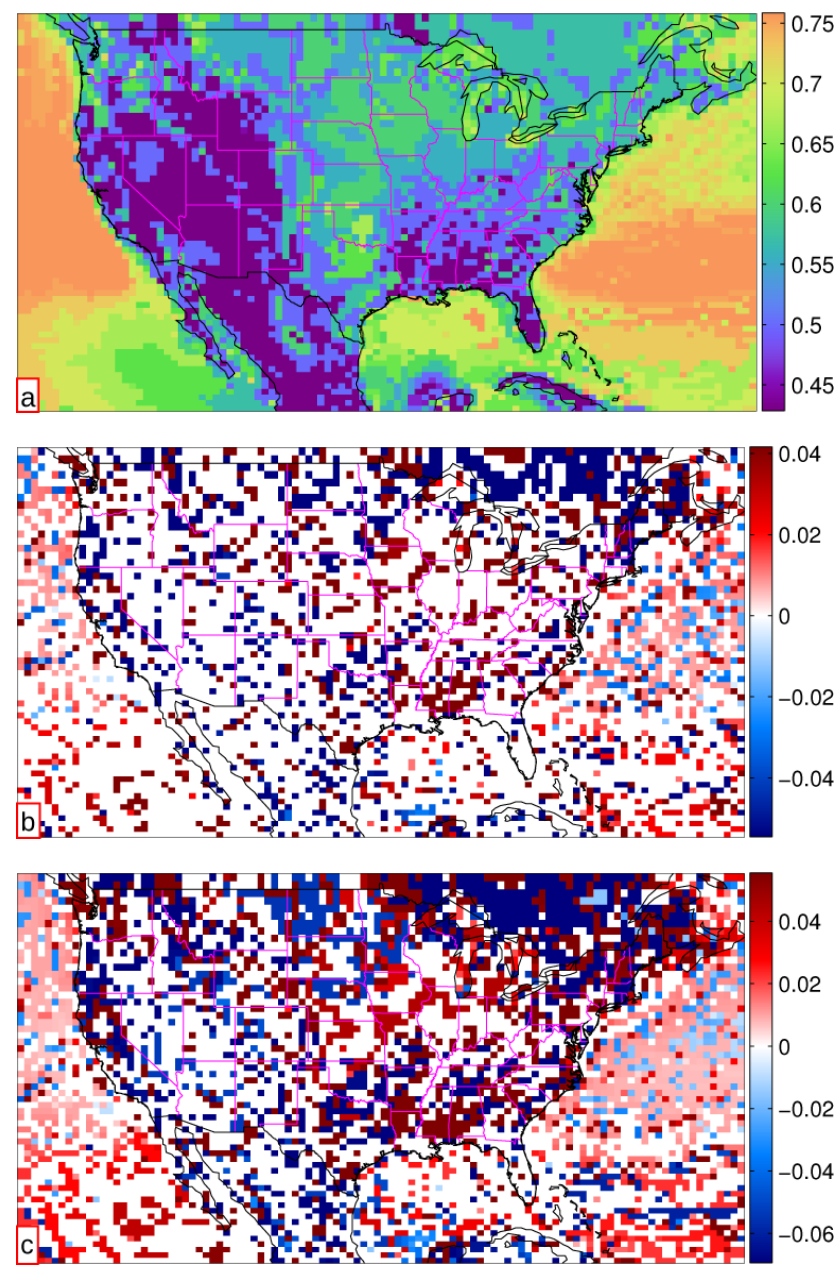

Fig. 16. Variation of the coefficient of variation of WPD episode lengths at different heights. (a) shows the $\mathrm{RCoV}$ of episode lengths at $80 \mathrm{~m}$ and (b) and (c) show the difference $\mathrm{RCoV}$ of episode lengths at $100 \mathrm{~m}$ and $120 \mathrm{~m}$ from that at $80 \mathrm{~m}$.

As the altitude is increased from $50 \mathrm{~m}$ to $80 \mathrm{~m}$, there is a general increase in the wind resource while the increase is greater in the central US region and in New England along the Appalachian region. The variation in wind resource with altitude is dependent on the wind resource at the lower height and the surface roughness length of the boundary layer. The wind resource increased rapidly in the central US because of the higher wind speeds at lower altitudes and it increased in the New England due to the large roughness length. Another reason for the large increase in WPD with altitude in the central US is the presence of a strong nocturnal low level jet that has a maximum between $500 \mathrm{~m}$ and $800 \mathrm{~m}$.

As the hub height is increased from $80 \mathrm{~m}$ to $100 \mathrm{~m}$ and $120 \mathrm{~m}$, the mean WPD increases fast initially and then the increase subsides. Although the change decreases, there does not seem to be a saturation even with reasonable increases beyond $120 \mathrm{~m}$. The median wind power density also shows a similar change profile. 
As the mean WPD increases with altitude, it implies that the frequency distribution of the WPD shifts to the right. Also, the frequency distribution is broadened. Thus, the wind resource and the variability of the resource increase with a rise in hub height from $80 \mathrm{~m}$ to $120 \mathrm{~m}$. The increase in WPD corresponds to almost to more than one NREL wind-power class.

The CoV of WPD with altitude shows different variation in different regions. Interestingly, while the $\mathrm{CoV}$ decreases over the land, it increases slightly over the oceans. It implies that the variance increases faster than the mean in the offshore regions. Further, the $\mathrm{CoV}$ decreases with altitude in the northeastern states. Interestingly, the largest increase in persistence of WPD with altitude is in these northeastern states. The central US and offshore regions have similar mean and median episode lengths whereas the non-central continental US regions have longer mean episode lengths and shorter median episode lengths leading to the inference that the episode length distributions in the non-central US are very skewed and are dominated by a few long episode lengths. With altitude, the mean episode length decreases less in the resource-rich regions but more so in the low-resource regions (e.g. northeast). Conversely, the median increases almost everywhere by about an hour or less. This leads to the important inference that as the turbine hub height is increased, a few very long episodes are replaced by a greater number of shorter episodes and hence more intermittent wind resource.

\section{Appendix A}

\section{Wind power classes}

Table A1. Wind power classes at $50 \mathrm{~m}$ height.

\begin{tabular}{lrl}
\hline Class & WPD at $50 \mathrm{~m}_{\left(\mathrm{W} \mathrm{m}^{-2}\right)}$ & Quality \\
\hline 1 & $0-200$ & Poor \\
2 & $200-300$ & Marginal \\
3 & $300-400$ & Fair \\
4 & $400-500$ & Good \\
5 & $500-600$ & Excellent \\
6 & $600-800$ & Outstanding \\
7 & $>800$ & Superb \\
\hline
\end{tabular}

\section{Appendix B}

\section{WPD distribution}

The following figure shows that the distribution of WPD is longtailed and skewed.

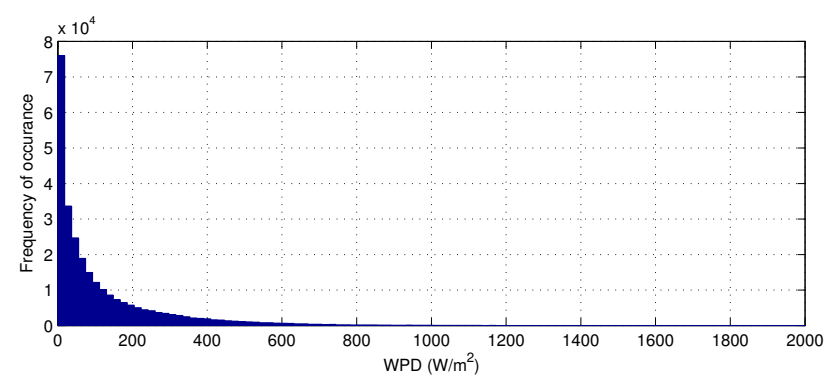

Fig. B1. Illustrative distribution of the WPD. The histogram corresponds to an example grid point in the central US.

Acknowledgements. The authors gratefully acknowledge support of the MIT Joint Prgram on the Science and Policy of Global Change by government, industry, foundation funding, MIT Energy Initiative and industrial sponsors. We also acknowledge that the constructive criticism by the reviewers helped us make the document very coherent and clear. We thank them for their valuable comments.

Edited by: D. J. Cziczo

\section{References}

Archer, C. L. and Jacobson, M. Z.: Spatial and Temporal Distributions of US Winds and Wind Power at $80 \mathrm{M}$ Derived from Measurements, J. Geophys. Res., 108, 42-89, 2003.

Archer, C. L. and Jacobson, M. Z.: Supplying Baseload Power and Reducing Transmission Requirements by Interconnecting Wind Farms, J. Appl. Meteorol. Clim., 46, 1701-1717, 2007.

Atkinson, N., Harman, K., Lynn, M., Schwarz, A., and Tindal, A.: Long-term Wind Speed Trends in Northwestern Europe, Technical report, Garrad Hassan, 2006.

Boccard, N.: Capacity Factor of Wind Power Realized Values Vs. Estimates, Energ. Policy, 37, 2679-2688, 2009.

Brower, M.: Development of Eastern Regional Wind Resource and Wind Plant Output Datasets, US Department of Energy, National Renewable Energy Laboratory: Golden, CO, 2008.

Chang, T. J., Wu, Y. T., Hsu, H. Y., Chu, C. R., and Liao, C. M.: Assessment of Wind Characteristics and Wind Turbine Characteristics in Taiwan, Renew. Energ., 28, 851-871, 2003.

Dorvlo, A. S.: Estimating Wind Speed Distribution, Energ. Convers. Manage., 43, 2311-2318, 2002.

Elliott, D. L., Holladay, C. G., Barchet, W. R., Foote, H. P., and Sandusky, W. F.: Wind Energy Resource Atlas of the United States, NASA STI/Recon Technical Report N, 87, 24 819, 1987.

Elliott, D. L., Wendell, L. L., and Gower, G. L.: An Assessment of the Available Windy Land Area and Wind Energy Potential in the Contiguous United States, Tech. rep., Pacific Northwest Lab., Richland, WA (United States), 1991.

Eskin, N., Artar, H., and Tolun, S.: Wind Energy Potential of Gökçeada Island in Turkey, Renew. Sust. Energ. Rev., 12, 839851, 2008. 
Gustavson, M. R.: Limits to Wind Power Utilization, Science, 204, 13-17, 1979.

He, Y., Monahan, A. H., Jones, C. G., Dai, A., Biner, S., Caya, D., and Winger, K.: Probability Distributions of Land Surface Wind Speeds over North America, J. Geophys. Res., 115, D04103, doi:10.1029/2008JD010708, 2010.

Hennessey Jr., J.: Some Aspects of Wind Power Statistics, J. Appl. Meteorol., 16, 119-128, 1977.

Jaramillo, O. A. and Borja, M. A.: Wind Speed Analysis in La Ventosa, Mexico: A Bimodal Probability Distribution Case, Renew. Energ., 29, 1613-1630, 2004.

Justus, C., Hargraves, W., and Yalcin, A.: Nationwide Assessment of Potential Output from Wind-Powered Generators, J. Appl. Meteorol., 15, 673-678, 1976.

Kiss, P. and Jánosi, I. M.: Limitations of wind power availability over Europe: a conceptual study, Nonlin. Processes Geophys., 15, 803-813, doi:10.5194/npg-15-803-2008, 2008.

Larsen, X. G. and Mann, J.: Extreme Winds from the NCEP/NCAR Reanalysis Data, Wind Energ., 12, 556-573, 2009.

Lun, I. and Lam, J.: A Study of Weibull Parameters Using LongTerm Wind Observations, Renew. Energ., 20, 145-153, 2000.

Morrissey, M., Cook, W., and Greene, J.: An Improved Method for Estimating the Wind Power Density Distribution Function, J. Atmos. Ocean. Tech., 27, 1153-1164, 2010.

NREL: Wind Powering America: 80-Meter Wind Maps and Wind Resource Potential, http://www.windpoweringamerica. gov/wind_maps.asp, http://www.windpoweringamerica.gov/ wind_maps.asp, last access: 22 June 2011, 2010.

Pavia, E. G. and O'Brien, J. J.: Weibull Statistics of Wind Speed over the Ocean., J. Appl. Meteorol., 25, 1324-1332, 1986.

Pryor, S. C. and Barthelmie, R. J.: Climate Change Impacts on Wind Energy: A Review, Renew. Sust. Energ. Rev., 14, 430-437, 2010.
Rienecker, M. M., Suarez, M. J., Gelaro, R., Todling, R., Bacmeister, J., Liu, E., Bosilovich, M. G., Schubert, S. D., Takacs, L., Kim, G., Bloom, S., Chen, J., Collins, D., Conaty, A., da Silva, A., Gu, W., Joiner, J., Koster, R. D., Lucchesi, R., Molod, A., Owens, T., Pawson, S., Pegion, P., Redder, C. R., Reichle, R., Robertson, F. R., Ruddick, A. G., Sienkiewicz, M., and Woollen, J.: MERRA - NASA's Modern-Era Retrospective Analysis for Research and Applications, J. Climate, 24, doi:10.1175/JCLI-D11-00015.1, 2011.

Schwartz, M. and Elliot, D.: Remapping of the Wind Energy Resource in the Midwestern United States: Preprint, Tech. rep., National Renewable Energy Lab., Golden, CO (US), 2001.

Schwartz, M. and Elliot, D.: Towards a Wind Energy Climatology at Advanced Turbine Hub-Heights, in: Preprint, 15th Conference on Applied Climatology, Savannah, GA, American Meteorological Society, 2005.

Sigl, A. B., Corotis, R. B., and Won, D. J.: Run Duration Analysis of Surface Wind Speeds for Wind Energy Application, J. Appl. Meteorol., 18, 156-166, 1979.

Stull, R.: An Introduction to Boundary Layer Meteorology, 13, Springer, Boston, 1988.

The American Wind Energy Association: The Economics of Wind Energy. Technical Report, Tech. rep., American Wind Energy Association., http://www.fishermensenergy.com/dms/ showfile.php?id=44, 2005.

Tuller, S. E. and Brett, A. C.: The Characteristics of Wind Velocity That Favor the Fitting of a Weibull Distribution in Wind Speed Analysis., J. Appl. Meteorol., 23, 124-134, 1984.

Ucar, A. and Balo, F.: Investigation of Wind Characteristics and Assessment of Wind-Generation Potentiality in Uludag-Bursa, Turkey, Appl. Energ., 86, 333-339, 2009.

Zaharim, A., Razali, A. M., Abidin, R. Z., and Sopian, K.: Fitting of Statistical Distributions to Wind Speed Data in Malaysia, European Journal of Scientific Research, 26, 6-12, 2009. 